\title{
DOPAMINE ACTION ON HIPPOCAMPAL PYRAMIDAL CELLS ${ }^{1}$
}

\author{
L. S. BENARDO ${ }^{2}$ AND D. A. PRINCE ${ }^{3}$
}

Department of Neurology, Stanford University School of Medicine, Stanford, California 94305

Received September 17, 1981; Revised November 25, 1981; Accepted December 7, 1981

\begin{abstract}
Dopamine (DA) was applied to CA1 region pyramidal cells in slices of guinea pig hippocampus maintained in vitro in order to examine its electrophysiological effects on CNS neurons. DA induced hyperpolarization of membrane potential and an increased conductance in $75 \%$ the $21 \mathrm{CA} 1$ neurons to which it was applied. DA also augmented the afterhyperpolarizations and increased conductance which normally follow spike trains in these neurons. These effects were not altered by intracellular injections of $\mathrm{Cl}^{-}$but were blocked when slices were bathed in $\mathrm{Mn}^{2+}$ solutions. The $\mathrm{Mn}^{2+}$ blockade of DA-induced hyperpolarizations could be overcome when large amounts of agonists were applied. The DA effects were long lasting, were mimicked by the dopamine agonists apomorphine and Epinine, and were blocked by the dopamine antagonists flupenthixol and chlorpromazine. Extracellular or intraccllular application of cyclic AMP mimicked the effects of DA.

The results suggest that DA-induced hyperpolarization and conductance changes are mediated by a $\mathrm{Ca}^{2+}$-activated $\mathrm{K}^{+}$conductance. DA may increase the intracellular $\mathrm{Ca}^{2+}$ concentration through effects on one of the $\mathrm{Ca}^{2+}$ buffering mechanisms. The long duration of these effects suggests that DA works through some intracellular intermediary, perhaps cyclic AMP, considering that the actions of cyclic AMP on membrane properties are similar to those of DA. The dopaminergic projection to the hippocampus should have a powerful inhibitory action, which would be most effective in modulating the activities of neurons exhibiting high levels of excitability, particularly cells involved in cyclical burst generation.
\end{abstract}

Over the past decade, a wealth of information has accumulated to support a neurotransmitter role for dopamine (DA) in the mammalian brain. In addition, there is a great deal of evidence indicating that the dopaminergic system is involved in disorders such as Parkinson's disease and psychosis. Unfortunately, most of our knowledge of the dopaminergic system comes from biochenical and pharmacological studies of dopamine receptors; by contrast, the precise neurophysiological functions served by the dopaminergic neuronal pathways in the central nervous system are, as yet, only poorly defined (Iversen, 1975). To date, only a handful of studies have employed intracellular techniques to examine the action of DA on central nervous system neurons, and none of these have approached the underlying mechanisms (Kitai et al.,

\footnotetext{
${ }^{1}$ This work was supported by National Institutes of Health Grant NS 12151 from the National Institute of Neurological and Communicative Disorders and Stroke to D. A. P. and a National Science Foundation Fellowship to L. S. B. We are grateful to Drs. Barry Connors and Leona Masukawa for helpful discussion during the course of these experiments and to Ms. Cheryl Joo who typed the manuscript.

${ }^{2}$ Present address: Columbia University College of Physicians and Surgeons, 630 West 168th Street, New York, NY 10032.

${ }^{3}$ To whom correspondence should be addressed.
}

1976; Bernardi et al., 1978; Herrling et al., 1978; Gallagher et al., 1980; Herrling and Hull, 1980).

Recent investigations have identified a dopaminergic projection in the hippocampal formation. The existence of DA-sensitive receptor sites in the hippocampus is supported by the findings that iontophoretic application of DA to single hippocampal neurons recorded extracellularly decreases firing rates (Biscoe and Straughan, 1966; Segal and Bloom, 1974) and that a DA-sensitive adenylate cyclase, which is blocked by neuroleptics, is present in this structure (Dolphin and Bockaert, 1981). In addition, certain histofluorescence studies also have suggested the existence of a DA projection to the hippocampal formation. Thus, because of an apparent lack of dopamine $\beta$-hydroxylase, Swanson and Hartman (1975) suggested that many catecholaminergic afferents to the hippocampal formation, previously thought to be noradrenergic fibers, are actually dopamine-containing fibers. A recent biochemical study has shown that DA afferents to the hippocampal formation originate from the substantia nigra (A9) and the ventral tegmental area (A10) (Scatton et al., 1980). Anatomic studies provide further support for a dopaminergic input to the hippocampus. Antidromic transport of horseradish peroxidase 
occurs from the hippocampus to neurons in the ventral tegmental area and substantia nigra (Wyss et al., 1979), and cell bodies in the A10 area of the brain stem also are labeled by antidromic transport of ${ }^{125} \mathrm{I}$-wheat germ agglutinin (Schwab et al., 1978). Anterograde transport of [ $\left.{ }^{3} \mathrm{H}\right]$ leucine (Simon et al., 1979) occurs from ventral tegmental A10 region to the hippocampus.

In light of the above, it seemed reasonable to use the hippocampus as a model in which to investigate the action of dopamine on CNS neurons. In previous experiments, we examined the phenomenology associated with dopamine application to CA1 region hippocampal pyramidal cells in the in vitro slice preparation (Benardo and Prince, 1982; L. S. Benardo and D. A. Prince, submitted for publication). The main findings of that study were that DA in concentrations as low as $1 \mu \mathrm{M}$ caused small hyperpolarizations which could be associated with small increases in membrane conductance and that DA increased the duration, amplitude, and conductance changes associated with the slow afterhyperpolarizations (AHPs) which normally follow repetitive spike discharges in these neurons (Hotson and Prince, 1980). We hypothesized that all of these actions of DA were mediated through effects on a $\mathrm{Ca}^{2+}$-activated $\mathrm{K}^{+}$conductance. In the present experiments, we have obtained further data to support this proposal by investigating the ionic mechanism associated with DA action. In addition, we have studied the pharmacology of DA action and have attempted to elucidate the mechanism underlying the long term changes caused by DA. The results suggest that DA acts through a DA receptor and that the long term changes induced by DA may be mediated through cyclic AMP.

\section{Materials and Methods}

Transverse slices ( $350 \mu \mathrm{m}$ thick) of guinea pig hippocampus were prepared and maintained as has been described previously (Yamamoto, 1972; Schwartzkroin, 1975). Slices were incubated at $37^{\circ} \mathrm{C}$ in a control medium containing (in millimolar concentrations): $\mathrm{NaCl}, 124$; $\mathrm{KCl}, 5 ; \mathrm{NaH}_{2} \mathrm{PO}_{4}, 1.25 ; \mathrm{MgSO}_{4}, 2 ; \mathrm{CaCl}_{2}, 2 ; \mathrm{NaHCO}_{3}, 26$; dextrose, 10. Perfusion solutions were saturated with $95 \%$ $\mathrm{O}_{2}, 5 \% \mathrm{CO}_{2}$. For experiments involving $\mathrm{Mn}^{2+}$, a modified control medium substituting $\mathrm{Cl}^{-}$for phosphate and sulfate was used to prevent precipitation of divalent cations. Changing from one control medium to the other did not alter neuronal properties. The following drugs were applied extracellularly to the bathing medium: chlorpromazine $\left(10^{-6} \mathrm{M}\right)$, cis $\alpha$-flupenthixol $\left(10^{-7} \mathrm{M}\right)$, and 8-bromoadenosine $3^{\prime}: 5^{\prime}$-cyclic monophosphate $\left(10^{-4} \mathrm{M}\right)$. The following drugs were applied extracellularly by direct drop application (Benardo and Prince, 1981): dopamine hydrochloride $\left(10^{-6}\right.$ to $\left.10^{-4} \mathrm{M}\right)$, apomorphine hydrochloride $\left(10^{-5}\right.$ to $\left.10^{-4} \mathrm{M}\right)$, and Epinine $\left(10^{-4} \mathrm{M}\right)$. A variety of data showed that the DA effects to be described below were not due to artifacts of the drop application technique. In $25 \%$ of the cells, DA application produced no changes in membrane potential or conductance, even though identical application techniques were used in all neurons. In other neurons, DA effects only occurred after the second or third drop application. Finally, as will be shown, the effects of DA and agonists were blocked by specific antagonists.
Intracellular recordings were obtained from physiologically identified pyramidal cells in stratum pyramidale of the CA1 region (Schwartzkroin, 1975). Recording electrodes ( 25 to 60 megohms) were filled with $3 \mathrm{~m} \mathrm{KCl,} 4 \mathrm{M}$ potassium acetate, $4 \mathrm{M}$ potassium acetate plus $0.2 \mathrm{M}$ ethylene glycol bis( $\beta$-aminoethyl ether)- $N, N, N^{\prime}, N^{\prime}$-tetraacetic acid (EGTA), or $4 \mathrm{M}$ potassium acetate plus $10^{-3}$ M adenosine $3^{\prime}: 5^{\prime}$-cyclic monophosphate ( $\left.\mathrm{pH} 7\right)$. All drugs were obtained from Sigma with the exception of cis- $\alpha$ flupenthixol which was kindly supplied by Richard Bohm in the Department of Psychiatry at Stanford Medical Center. Standard recording techniques were employed. Current was applied through the recording microelectrode utilizing an active bridge circuit; bridge balance was monitored and adjusted continuously. Only neurons with stable resting potentials of $-55 \mathrm{mV}$ and action potentials of $70 \mathrm{mV}$ or greater were included in this study. Orthodromic stimuli were delivered through sharpened, bipolar tungsten electrodes placed in stratum radiatum.

\section{Results}

The major actions of DA are illustrated in Figure 1. DA was found to be effective on approximately $75 \%$ of the $21 \mathrm{CA} 1$ neurons to which it was applied. Following DA application, hyperpolarization of membrane potential $\left(\mathrm{V}_{\mathrm{m}}\right)$ usually was observed (Fig. $1 A$ ). Further summated increases in $V_{m}$ could be evoked by trains of intracellular depolarizing pulses which elicited spikes (cf., Fig. 1, $B$ and $C$ ). The maximum total hyperpolarization measured was $7.7 \pm 6.0$ (SD) $\mathrm{mV}(n=13)$. Associated with this maximum change in $V_{m}$, there was a significant mean decrease in cell input resistance $\left(\mathrm{R}_{\mathrm{N}}\right)$ of $22.2 \%$ (Fig. $1 C)$ which was independent of membrane rectification. Concomitant with DA-induced alterations in membrane parameters, the slow afterhyperpolarizations (AHPs) evoked in these cells were greatly enhanced in duration and amplitude (cf., Fig. 1, $B, C$, and $D$ ). In addition, the conductance increases associated with these enhanced slow AHPs were larger than those recorded under control conditions. Although it was possible to study the same neuron before and after drug application in some cases (e.g., Fig. 1, $B$ and $C$ ), in other instances, the "control" neuron was lost and comparisons were made between different cells impaled before and after exposure to DA or an agonist (e.g., Figs. $1 D$ and $5 A$ ). In these instances, we kept the number of spikes in the burst which evoked the AHP constant by increasing the current intensity as necessary to compensate for the increased conductance which followed larger doses of DA or agonists (e.g., Figs. $5 A$ and $6 A$ ). Fortunately, the duration of AHPs following the exposure of slices to $10^{-4}$ to $10^{-5} \mathrm{M} \mathrm{DA}$ was very much longer than that in any control recordings. Previous data from our laboratory (Hotson and Prince, 1980) indicate that AHPs from neurons of slices bathed in normal medium at $37^{\circ} \mathrm{C}$ usually have durations of $1 \mathrm{sec}$ or less. AHPs are not prolonged significantly beyond this even when longer or more intense depolarizing pulses, which trigger larger numbers of spikes, are used to evoke them. The control data in the present experiments were similar to those previously reported in that single AHPs in slices not exposed to DA or agonists were almost always $<2 \mathrm{sec}$ in duration. By contrast, as shown in 


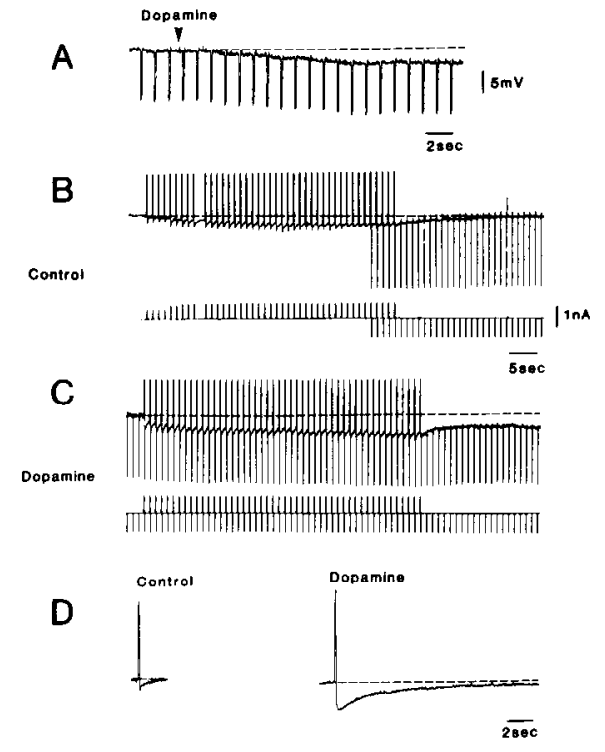

Figure 1. Dopamine actions on hippocampal neurons. A, Hyperpolarizing response of a cell to application of $10^{-5} \mathrm{M} \mathrm{DA}$. The voltage response to constant current hyperpolarizing pulses shows that no detectable change of input resistance accompanies this hyperpolarization. Resting potential, $-60 \mathrm{mV}$. $B$, In another neuron under normal conditions, a $1-\mathrm{Hz}$ train of 120 msec-duration depolarizing current pulses, of sufficient intensity to elicit 2 to 10 spikes, results in membrane hyperpolarization associated with a decrease in resistance. When depolarizing pulses are discontinued, the membrane repolarizes and resistance recovers to the control level. $C$, After DA application onto the cell of $B$, the membrane potential hyperpolarized by a few millivolts (not shown) and then was depolarized to the control level (dashed line) with DC current. A train of depolarizing pulses comparable to that in $B$ was delivered. $R_{N}$ decreased during the train and membrane potential and resistance at the end of the train of depolarizing pulses did not recover to prestimulus levels. Control resting potential, -56 $\mathrm{mV} . D$, Examples of slow afterhyperpolarizations in control and DA-treated neurons, elicited by depolarizing current pulses which evoke 5 to 6 spikes. The dashed lines represent base line resting potentials. These segments and those in subsequent figures except Figure $2 A$ are from a strip chart recorder. Spike amplitudes are amputated or attenuated by low frequency response. The voltage calibration in $A$ is for all segments. The calibrations in $B$ are for $B$ and $C$.

Figures $1 D$ and $5 A$, AHPs following drug treatment often lasted $10 \mathrm{sec}$ or longer. The above effects of DA could last $1 \mathrm{hr}$ or longer following a single application and, in prolonged penetrations, were found to be reversible over time. These phenomena were analyzed further in the experiments presented below.

Chloride injection. In previous experiments on hippocampal pyramidal cells, we found that the reversal potential for dopamine-induced hyperpolarization, obtained from the intersection of current-voltage lines, was -86.8 $\pm 11.1(\mathrm{SD}) \mathrm{mV}(n=8)$. We suggested that a reversal potential at this negative level was consistent with dopamine action on a $\mathrm{K}^{+}$rather than a $\mathrm{Cl}^{-}$conductance. The reversal potential for the slow AHP, which is known to be mediated by a $\mathrm{K}^{+}$conductance, is very similar to this value (Alger and Nicoll, 1980a). However, the $\mathrm{Cl}^{-}$ equilibrium potential, estimated from the reversal potential for GABA-induced hyperpolarization, is considerably lower than this potential (about $-70 \mathrm{mV}$; Andersen et al., 1980). In the present experiments, we obtained additional, more direct evidence that $\mathrm{Cl}^{-}$does not contribute significantly to DA-induced hyperpolarizations by impaling neurons with $\mathrm{KCl}$-filled microelectrodes. Since IPSPs in the hippocampus are known to be $\mathrm{Cl}^{-}$mediated, $\mathrm{Cl}^{-}$diffusion or electrophoresis from the microelectrode would produce a positive shift in the chloride equilibrium potential and result in reversal of the IPSP or an apparent broadening of the EPSP (Alger and Nicoll, 1979). If the DA-induced hyperpolarization were mediated by an increase in $\mathrm{Cl}^{-}$conductance, it also would be decreased in amplitude or reversed by $\mathrm{Cl}^{-}$injection. Figure 2 shows some of the consequences of $\mathrm{Cl}^{-}$injection. Following impalement with $\mathrm{KCl}$ electrodes, spontaneous activity appeared to be increased in some cells, a finding which has been attributed to reversal of spontaneous IPSPs which appear as depolarizing potentials (Alger and Nicoll, 1980b). In addition to this effect, we found that EPSPs evoked by stratum radiatum stimuli were much longer in duration than those obtained from control neurons (Fig. 2A, left and center frames) and that bursts might be triggered by such prolonged EPSPs (Fig. $2 A$, right frame; Wong and Prince, 1979). These results suggest that the $\mathrm{Cl}^{-}$reversal potential was shifted to a level positive to resting potential. Under these conditions, DA was applied to 4 neurons, and hyperpolarization developed in 3 of them. In the neuron of Figure $2 B$, a hyperpolarization of $4.5 \mathrm{mV}$ and an associated small increase in conductance $(<10 \%)$ began 3 sec following DA application. Stimulus-induced hyperpolarization due to AHP augmentation similar to that of Figure $1 D$ also could be observed following DA administration after $\mathrm{Cl}^{-}$injections (not shown). Thus, a change in $\mathrm{Cl}^{-}$conductance does not appear to play a significant role in the DA effects and, by inference, DA-induced hyperpolarizations would be mediated by an increase in $\mathrm{K}^{+}$conductance.

$\mathrm{Mn}^{2+}$ solutions. As previously mentioned, slow AHPs which followed repetitive action potentials elicited by depolarizing current pulses were greatly enhanced following DA application (Fig. $1 D$ ). Such slow AHPs in nonDA-treated neurons have been shown to be mediated by a $\mathrm{Ca}^{2+}$-activated $\mathrm{K}^{+}$conductance (Alger and Nicoll, 1980a; Hotson and Prince, 1980). We speculated that augmentation of this conductance by DA could mediate the long lasting AHPs which the drug induces. An alternative explanation might be that such stimulus-induced AHPs result from augmentation of a $\mathrm{Na}^{+} / \mathrm{K}^{+}$pump as has been suggested to explain the actions of norepinephrine (Segal, 1981). Against this interpretation is the finding that DA-augmented slow AHPs are associated with concomitant increases in conductance as are normal slow AHPs. These observations do not rule out the synergistic actions of DA on a pump and a $\mathrm{Ca}^{2+}$-activated $\mathrm{K}^{+}$conductance. To investigate this more rigorously, we used solutions containing low $\mathrm{Ca}^{2+}(1 \mathrm{mM})$ and $\mathrm{Mn}^{2+}(3 \mathrm{~mm})$ to block $\mathrm{Ca}^{2+}$ influx. Under these conditions, $\mathrm{Na}^{+}$spikes, a presumed stimulus for $\mathrm{Na}^{+} / \mathrm{K}^{+}$pump activation (Thomas, 1972) are preserved. If a stimulus-evoked spike train induced an AHP and if this AHP were enhanced by $\mathrm{DA}$, an action on a pump might be implied. Alternatively, if DA-induced slow AHPs depended solely on $\mathrm{Ca}^{2+}$ influx, stimulus-induced slow hyperpolarizations would not be 

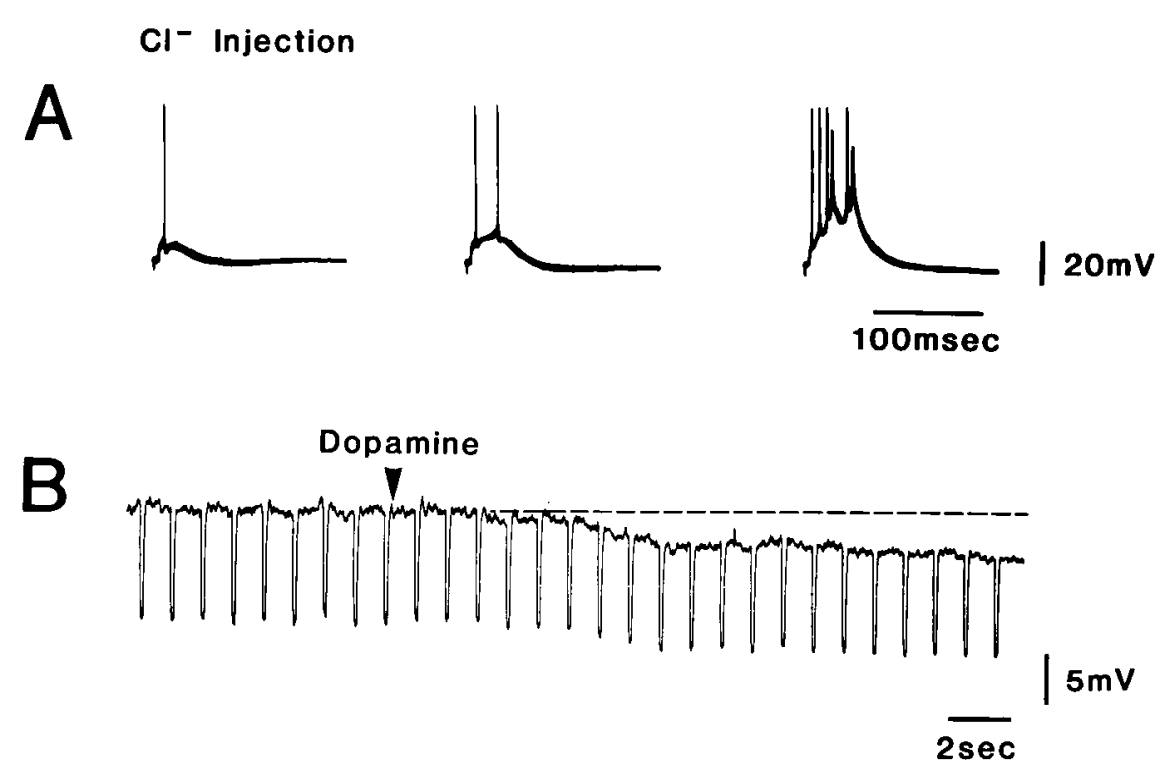

Figure 2. Persistence of DA hyperpolarization following $\mathrm{Cl}^{-}$injection. $A$, Orthodromically evoked EPSPs gradually broadened following impalement with a microelectrode filled with $3 \mathrm{M} \mathrm{KCl} \mathrm{(left} \mathrm{and} \mathrm{center} \mathrm{frames),} \mathrm{and} \mathrm{burst} \mathrm{discharges}$ developed (right frame). Resting potential, $-62 \mathrm{mV}$. $B$, Hyperpolarizing response of a cell impaled with a $\mathrm{KCl}$ electrode to the application of $10^{-5} \mathrm{M} \mathrm{DA}$. The voltage response to constant current hyperpolarizing pulses shows a small decrease in input resistance associated with this hyperpolarization. Control resting potential (dashed line), $-58 \mathrm{mV}$.

observed. In 9 cells, slow AHPs were blocked by the $\mathrm{Mn}^{2+}$-containing solution (cf., Fig. $3 B$ "control" with Fig. $1 B$; Hotson and Prince, 1980). Under these conditions, DA application did not restore slow AHPs, even though depolarizing pulses evoked trains of spikes (cf., Fig. $3 B$ "dopamine" with Fig. $1 C$ ). This result argues strongly against the possibility that DA affects an electrogenic pump.

Although $\mathrm{Mn}^{2+}$ blocked both control and DA-augmented poststimulus slow AHPs, DA still induced spontaneous hyperpolarizing responses in 3 of 9 cells recorded in $\mathrm{Mn}^{2+}$ (Fig. $3 A$; mean $=8.3 \mathrm{mV}$ ). Such $\mathrm{Mn}^{2+}$-resistant hyperpolarizations were seen only after repeated application of large volumes of agonist and were associated with a mean conductance increase of $19 \%$. The precise mechanism underlying this DA-induced, $\mathrm{Mn}^{2+}$-resistant hyperpolarization is unclear. Since $3 \mathrm{mM} \mathrm{Mn}^{2+}$ is known to block synaptic transmission in this preparation (Hotson and Prince, 1980; Gutnick and Prince, 1981), the DA actions observed must be postsynaptic. One explanation might be that DA activates a non- $\mathrm{Ca}^{2+}$-dependent $\mathrm{K}^{+}$ conductance directly. Alternatively, DA might act to increase the intracellular $\mathrm{Ca}^{2+}$ concentration, thereby inducing a $\mathrm{Ca}^{2+}$-activated $\mathrm{K}^{+}$conductance (see "Discussion").

$E G T A$ injection. In order to investigate the dependence of DA-induced effects on intracellular $\mathrm{Ca}^{2+}$ concentration $\left(\left[\mathrm{Ca}^{2+}\right]_{\mathrm{i}}\right)$, the $\mathrm{Ca}^{2+}$ chelating agent EGTA was injected electrophoretically into CA1 cells. EGTA readily depresses or blocks $\mathrm{Ca}^{2+}$-activated $\mathrm{K}^{+}$conductance in these neurons (Alger and Nicoll, 1980a; Schwartzkroin and Stafstrom, 1980; Hablitz, 1981). Nine cells were impaled successfully with EGTA-containing electrodes and the drug was iontophoresed utilizing negative current ( 1

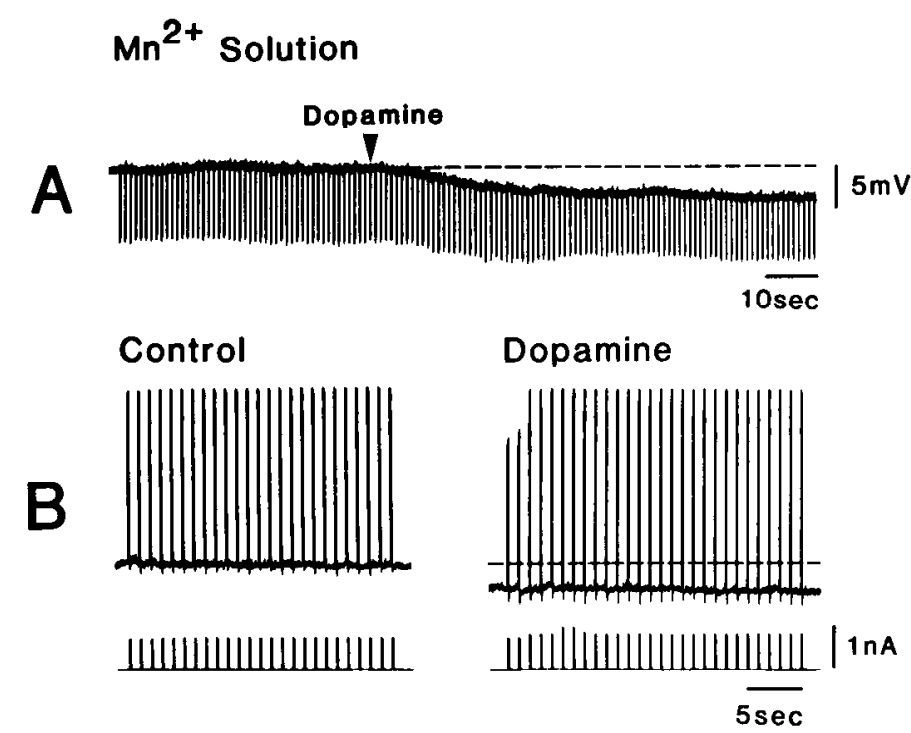

Figure 3. Results of $10^{-4}$ M DA application to slices exposed to low $\mathrm{Ca}^{2+} / \mathrm{Mn}^{2+}$-containing solution. $A$, Hyperpolarizing response to $\mathrm{DA}$. The voltage response to constant current hyperpolarizing pulses shows that a decrease in resistance is associated with the hyperpolarization. $B$, Same cell as in $A$ showing the response to depolarizing current pulses before and after DA application. Slow afterhyperpolarizations are blocked under both conditions (cf., with Fig. 1, $B$ and $C$ ). Control resting potential (dashed line), $-64 \mathrm{mV}$. The voltage calibration in $A$ is also for $B$.

to $1.5 \mathrm{nA}$ ) for periods of 1 to $2 \mathrm{~min}$. The amplitudes and durations of slow AHPs were attenuated. In addition, some cells depolarized approximately $5 \mathrm{mV}$ from resting potential (Krnjevic et al., 1978) and fired spontaneous bursts. When DA was applied to cells impaled with 
EGTA-containing electrodes, none of the DA effects described above were noted. EGTA also readily reversed the long lasting AHPs which had been produced by prior DA application. Figure 4 shows one such result. In this cell, a depolarizing current pulse delivered $5 \mathrm{~min}$ after DA application evoked a slow AHP which lasted 3 sec (Fig. 4A1). In other experiments, we have found that DA-induced prolongation of the AHP ordinarily lasts at least $60 \mathrm{~min}$ (Benardo and Prince, 1982; L. S. Benardo and D. A. Prince, submitted for publication). Following a 1-min injection of EGTA, the duration of slow AHPs decreased to $1 \mathrm{sec}$ (Fig. 4B1). Cumulative afterhyperpolarizations during trains of depolarizing current pulses likewise were reduced in this cell and recovery to resting potential after such trains was shortened (cf., Fig. 4, A2 and $B 2$ ). These results suggest that DA effects are dependent on $\left[\mathrm{Ca}^{2+}\right]_{\mathrm{i}}$.

$D A$ agonists and antagonists. To determine whether the effects described above were initiated specifically by interactions of DA and the DA-sensitive receptor, we studied the effects of several agonists and antagonists on neuronal $V_{m}, R_{N}$, and slow AHPs. Two well known DA agonists, apomorphine and Epinine, induced spontaneous hyperpolarizations and augmented the duration, amplitude, and conductance increases of triggered AHPs in 75 to $80 \%$ of the cells to which they were applied (Fig. $5 A$ ). These actions were similar in every way to the above DA effects.

To gain further information about the type of receptor with which DA interacts, slices were bathed in media containing one of two classes of known DA antagonists, either flupenthixol $\left(10^{-7} \mathrm{M}\right)$, a thioxanthene, or chlorpromazine $\left(10^{-6} \mathrm{M}\right)$, a phenothiazine. We did not detect any alteration in resting membrane parameters in cells

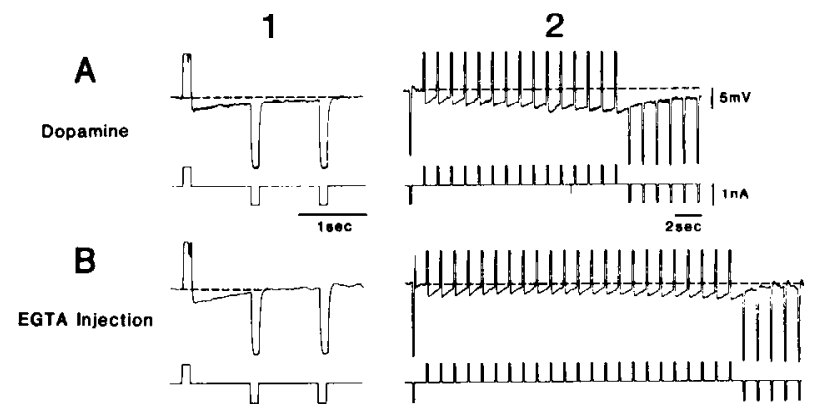

Figure 4. Actions of intracellular EGTA on DA effects. $A$ and $B$, Records obtained from a cell impaled with an EGTAcontaining microelectrode following application of DA $\left(10^{-5}\right.$ M). $A 1$, Before EGTA iontophoresis, a slow afterhyperpolarization lasting 2 sec follows a single depolarizing current pulse. A2, A train of depolarizing current pulses causes a decrease in resistance and a hyperpolarization of membrane potential which does not recover to prestimulus level. $B$, Following a 1min, 1.5-nA hyperpolarizing DC current to electrophorese EGTA. B1, Single depolarizing current pulse elicits a slow afterhyperpolarization lasting 1 sec. $B 2$, Response of a neuron to a train of depolarizing current pulses similar to those of $A 2$. Slow afterhyperpolarizations are of reduced amplitude and duration. The membrane potential recovers to the prestimulus level following the train. The dashed line represents the resting potential in $A$ and $B,-61 \mathrm{mV}$. The calibrations in $A$ are for $A$ and $B$.

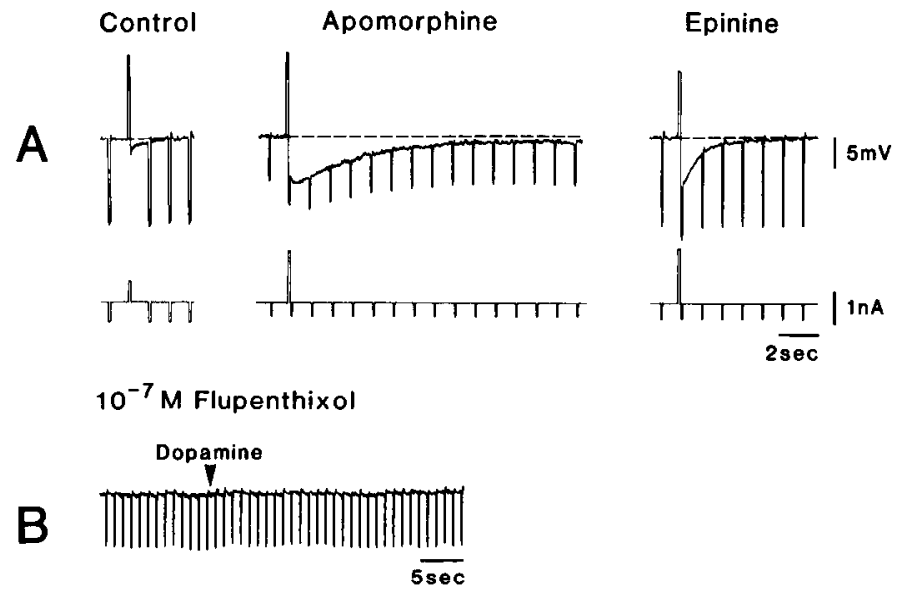

Figure 5. Effects of DA agonists and antagonists. A, Control: representative control slow afterhyperpolarization following current-induced repetitive spikes. $A$, Apomorphine: same neuron as control after application of $10^{-4} \mathrm{M}$ apomorphine. The dashed line represents the resting potential, $-60 \mathrm{mV}$. A, Epinine: slow afterhyperpolarization from another cell following $10^{-4} \mathrm{M}$ Epinine application. Resting potential, $-59 \mathrm{mV} . B$, Recording from a neuron bathed in medium containing $10^{-7} \mathrm{M}$ flupenthixol. Following $10^{-5} \mathrm{M} \mathrm{DA}$ application (arrow), no change in membrane potential or resistance occurs. Resting potential, $-62 \mathrm{mV}$. The voltage calibrations in $B$ are the same as those in $A$.

exposed to these blocking agents. DA in a concentration of $10^{-5} \mathrm{M}$ was applied to cells impaled under these conditions. In 4 neurons exposed to flupenthixol (Fig. $5 B$ ), and 6 cells exposed to chlorpromazine (not shown), DA application did not affect $V_{m}, R_{N}$, or slow AHPs, demonstrating that the actions of DA had been blocked. These results, together with those from experiments utilizing DA agonists, indicate that the effects of DA on pyramidal neurons described above are dependent upon interaction of DA with a DA receptor. It is interesting that both flupenthixol and chlorpromazine are potent blockers of DA-sensitive adenylate cyclase. This raised the possibility that the long term actions of DA might be mediated by the second messenger cyclic AMP.

Cyclic AMP. Biochemical evidence shows that DA stimulated adenylate cyclase in the central nervous system (Iversen, 1975). However, the precise role of cyclic AMP and the physiological effects of increases in its intracellular concentration have not been clearly elucidated (Iversen, 1975; Phillis, 1977). In the hippocampus, a DA-sensitive adenylate cyclase has been demonstrated (Dolphin and Bockaert, 1981); however, it has been proposed that cyclic AMP is the second messenger for the effects of norepinephrine (NE), which apparently has electrophysiological actions quite different from those of DA (Segal, 1981). We therefore examined the actions of cyclic AMP on hippocampal pyramidal cells to determine whether this agent would replicate the phenomenology of DA action. Neurons were exposed to cyclic AMP delivered either intra- or extracellularly. For extracellular applications, 8-bromoadenosine $3^{\prime}: 5^{\prime}$-cyclic monophosphate was added to the bathing medium so that a final concentration of $10^{-4} \mathrm{M}$ was reached. This compound is somewhat resistant to degradation by phosphodiesterase 


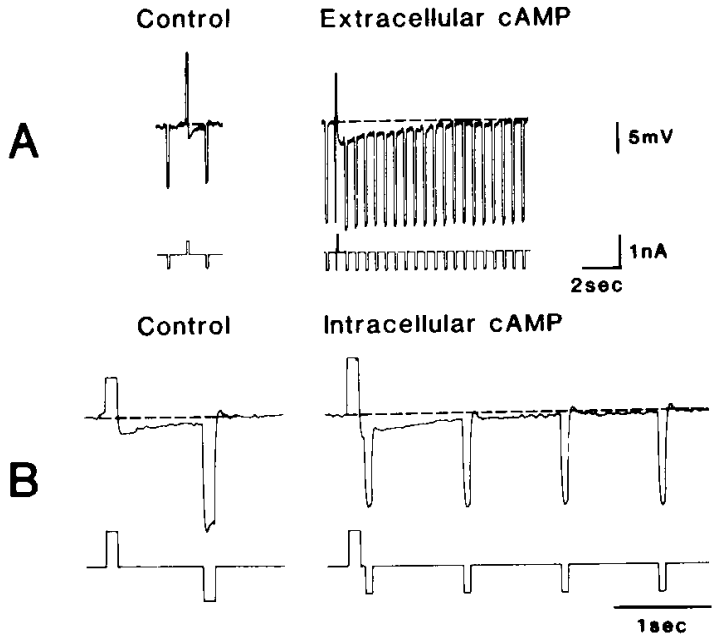

Figure 6. Effects of cAMP on slow afterhyperpolarization. A, Control: slow afterhyperpolarization in normal medium. Resting potential, $-64 \mathrm{mV}$. $A$, Extracellular cAMP: same cell as control $10 \mathrm{~min}$ following switch to media containing $10^{-4} \mathrm{M} 8$ bromoadenosine $3^{\prime}: 5^{\prime}$-cyclic monophosphate. The cell was tested at the new resting potential (dashed line) of $-72 \mathrm{mV}$. The amplitude and duration of AHP are enhanced. $B$, Control: slow afterhyperpolarization recorded with a microelectrode containing $10^{-3} \mathrm{M}$ adenosine $3^{\prime}: 5^{\prime}$-cyclic monophosphate. $B$, Intracellular cAMP: same neuron as control $5 \mathrm{~min}$ following impalement. Depolarizing pulses were delivered at the original resting potential of $-60 \mathrm{mV}$ in both segments of $B$. The voltage and current calibrations are the same in $A$ and $B$.

and will cross neuronal membranes (Nathanson, 1977). For intracellular applications, $10^{-3} \mathrm{M}$ adenosine $3^{\prime}: 5^{\prime}-$ cyclic monophosphate was added to $4 \mathrm{M}$ potassium acetate and this solution was used to fill recording microelectrodes. Similar results were obtained regardless of the method of delivery. Cyclic AMP produced a gradual hyperpolarization (over minutes) of membrane potential which often was associated with a decrease in resistance. As is shown in Figure 6, both intracellular and extracellular cyclic AMP produced a consistent lengthening of the slow AHP. The magnitude of these effects was somewhat variable, but in general, cyclic AMP actions mimicked those of DA.

\section{Discussion}

The results of these experiments support our hypothesis that DA enhances a $\mathrm{Ca}^{2+}$-activated $\mathrm{K}^{+}$conductance. Previous data indicated a very high reversal potential for DA-induced hyperpolarization which suggested an underlying $\mathrm{K}^{+}$conductance. The lack of effect of $\mathrm{Cl}^{-}$injection on DA hyperpolarizations and augmented AHPs in the present experiments rule out a significant contribution of this ion to DA actions. Further, the depression of DA actions in EGTA-treated neurons strongly supports the conclusion that a $\mathrm{Ca}^{2+}$-activated $\mathrm{K}^{+}$conductance is involved (Alger and Nicoll, 1980a; Schwartzkroin and Stafstrom, 1980).

One of the principal findings of the present study is the $\mathrm{Ca}^{2+}$-dependent nature of DA effects. Whereas DA normally induced changes in about $75 \%$ of the cells to which it was applied, it did not evoke hyperpolarization in neurons exposed to $3 \mathrm{~mm} \mathrm{Mn} \mathrm{Mn}^{2+}, 1 \mathrm{mM} \mathrm{Ca}^{2+}$ solution unless large volumes or repeated applications were used. This might indicate that $\mathrm{Ca}^{2+}$ plays an essential role in the interaction between DA and its receptor. In $\mathrm{Mn}^{2+}$ / low $\mathrm{Ca}^{2+}$ solution, the amounts of $\mathrm{Ca}^{2+}$ available might be adequate only in the presence of higher concentrations of agonist. An alternate, more attractive explanation for the $\mathrm{Mn}^{2+}$ effects would be that $\mathrm{Ca}^{2+}$ is required at a substantial stage of the response, specifically to produce the increase in $\mathrm{K}^{+}$conductance by increasing $\left[\mathrm{Ca}^{2+}\right]_{\mathrm{i}}$. Our data appear to be analogous to those from the cockroach salivary gland where the DA response can be depressed by decreases in extracellular $\mathrm{Ca}^{2+}$ concentration and restored when higher agonist concentrations are used (Ginsborg et al., 1980). Ginsborg et al. (1980) postulated that DA acted to increase $\left[\mathrm{Ca}^{2+}\right]_{\mathrm{i}}$ through the release of this ion from intracellular stores which could be replenished only by extracellular $\mathrm{Ca}^{2+}$. Our results from neurons in $\mathrm{Mn}^{2+}$ solutions can be explained by invoking a similar mechanism. The depression of DA responses after intracellular injection of EGTA supports the hypothesis that DA action is dependent on $\left[\mathrm{Ca}^{2+}\right]_{\mathrm{i}}$. Both the spontaneous hyperpolarizations and the augmentation of $\mathrm{Ca}^{2+}$-activated $\mathrm{K}^{+}$conductance produced by DA could result from an effect of DA to decrease $\mathrm{Ca}^{2+}$ buffering and increase $\left[\mathrm{Ca}^{2+}\right]_{\mathrm{i}}$. A variety of complex control mechanisms, including an ATP-driven $\mathrm{Ca}^{2+}$ pump, $\mathrm{Ca}^{2+} / \mathrm{Na}^{+}$carrier-mediated transport, and the binding of $\mathrm{Ca}^{2+}$ to proteins, are known to regulate $\left[\mathrm{Ca}^{2+}\right]_{\mathrm{i}}$ (Blaustein, 1976; Rasmussen and Goodman, 1977; Caroni and Carafoli, 1980; DiPolo, 1978) and DA might influence any of these processes directly or indirectly via effects on CAMP or another intracellular intermediary (Rasmussen, 1970; Rasmussen and Goodman, 1977).

Results of previous experiments (Hotson et al., 1979) suggest that a $\mathrm{Ca}^{2+}$ conductance may be partially activated at resting membrane potential in hippocampal pyramidal neurons. Activation of DA receptors and a decrease in $\mathrm{Ca}^{2+}$ buffering, in the face of this base line $\mathrm{Ca}^{2+}$ influx, would produce an increase in $\left[\mathrm{Ca}^{2+}\right]_{i}$, an increase in the $\mathrm{Ca}^{2+}$-activated $\mathrm{K}^{+}$conductance, and consequent hyperpolarization. We would speculate that a more intense activation of DA receptors could interfere further with $\mathrm{Ca}^{2+}$ buffering and cause an increase in $\left[\mathrm{Ca}^{2+}\right]_{\mathrm{i}}$ due to a release of $\mathrm{Ca}^{2+}$ from intracellular stores, a decrease in $\mathrm{Ca}^{2+}$ pumping, or some other mechanism, even when $\mathrm{Ca}^{2+}$ conductance across the cell membrane is blocked. This would account for the $\mathrm{Mn}^{2+}$-resistant hyperpolarization seen after application of large volumes of DA (Fig. $3 A$ ). A long lasting change in $\mathrm{Ca}^{2+}$ buffering also would lead to the augmented AHPs seen following DA, since these potentials are normally a consequence of $\mathrm{Ca}^{2+}$ entry (Hotson and Prince, 1980; Alger and Nicoll, 1980a). The mechanism proposed is consistent with theories regarding the dependence of $\mathrm{K}^{+}$conductance on internal $\mathrm{Ca}^{2+}$ accumulation (Meech, 1978; Gorman and Thomas, 1980).

Intracellular measurements of DA actions in the CNS have, until recently, been limited to caudate neurons. It is quite clear that the responses of hippocampal cells to DA described above are markedly different from those reported in caudate neurons where DA induces depolarization (Kitai et al., 1976; Herrling and Hull, 1980; Ber- 
nardi et al., 1978) and increases resistance (Herrling and Hull, 1980). In one other intracellular study, the action of DA on hippocampal neurons in anesthetized cats was examined (Herrling, 1981). DA produced hyperpolarizations and decreased firing in presumed pyramidal neurons. Input resistance was measured in 4 neurons and said to be increased by DA iontophoresis. However, these neurons were injured and significantly depolarized. Conclusions regarding a possible difference between DA actions in hippocampus in vivo and those described here therefore must await the results of further in vivo experiments.

From our results and those cited above in caudate neurons, it is clear that DA may lead to different physiological effects in different areas of the brain. Such differences are presumably a consequence of the activation of different types of receptors or the coupling of similar receptors to different ionic mechanisms.

The pharmacological data indicate that the DA effects reported here are due to specific interaction with DA receptors. Several DA recepptors have been identified in the mammalian central nervous system (Seeman, 1980). The antagonist $c i s-\alpha$-flupenthixol is quite specific for D1 receptors (Seeman, 1980; Hyttel, 1980). Since all actions of DA were blocked by this drug, we would suggest that the DA effects reported here are mediated through a D1 receptor and are not likely to be due to nonspecific activation of norepinephrine receptors. One important aspect of this finding is that the D-1 receptor is linked to adenylate cyclase (Iversen, 1975; Seeman, 1980). This led us to examine the effects of cAMP on cellular properties. The results revealed that the actions of cAMP application were similar to those of DA. Although we cannot rule out the possibility that cAMP effects were independent of DA action, the long duration effects of DA certainly implicate a second messenger, and cAMP would seem to be the primary candidate for this role.

Previous physiological (Segal, 1981) and pharmacological (Segal et al., 1981) studies have emphasized the role of cAMP in the mediation of norepinephrine (NE) effects in hippocampus; however, our experiments imply that cAMP underlies DA effects. Drop application of cAMP reportedly produced small hyperpolarizations with minimal conductance change which were blocked by ouabain (Segal, 1981). The techniques of superfusion or intracellular injection used in the current experiments both probably make more drug available to the cell than the drop application method, and this may account for the larger conductance increases and changes in slow AHP duration which we observed. We did not test the ouabain sensitivity of the cAMP response, but the increased conductance associated with the cAMP-induced hyperpolarization (Fig. 6) suggests that a pump is not involved. As noted above, DA actions may be blocked by $\mathrm{Mn}^{2+}$, suggesting that $\mathrm{Na}^{+} / \mathrm{K}^{+}$pump activation is not responsible for the DA hyperpolarization.

In a recent biochemical study, Segal and his colleagues (Segal et al., 1981) investigated the efficacy of various transmitter substances (most notably NE) in causing increases in cAMP levels. This study utilized high concentrations of agonist $\left(10^{-4} \mathrm{M} \mathrm{NE}\right)$ to induce rises in cAMP. Since these concentrations of NE are far in excess of those reported as effective in earlier experiments (1 $\mu \mathrm{M}$ in Segal, 1981), the argument could be made that such a high concentration of NE might activate DA receptors (Seeman, 1980). The study by Segal et al. (1981) did not examine the extent of DA stimulation of cAMP. A discrepancy also exists between the results of the biochemical study of NE effects on membrane properties within 4 to $60 \mathrm{sec}$ of application (Segal, 1981), while cAMP did not reach its asymptotic level until about 5 to 10 min after NE stimulation (Segal et al., 1981). The latency to the increase in cAMP seems more compatible with the time course of the maximal physiological effects of DA, which are very slow, requiring minutes to reach a peak (Benardo and Prince, 1982; L. S. Benardo and D. A. Prince, submitted for publication). We suggest that perhaps the high concentrations of NE applied by Segal et al. (1981) stimulated DA receptors as well as NE receptors and that the rise in cAMP levels may reflect DA receptor activation.

We can only speculate regarding the physiological significance of the hippocampal DA system. Activation of the DA projection would have a profound inhibitory influence on hippocampal neurons. Since DA appears to act through effects on $\left[\mathrm{Ca}^{2+}\right]_{\mathrm{i}}$ (and consequently on $\mathrm{Ca}^{2+}$ activated $\mathrm{K}^{\prime}$ conductance), it would be expected to modulate the excitability changes which follow neuronal events that are mediated in part by $\mathrm{Ca}^{2+}$, such as depolarizing afterpotentials (Wong and Prince, 1981), anomalous inward rectification (Hotson et al., 1979), synaptic potentials (Nicoll and Alger, 1981), and intrinsic bursting (Johnston et al., 1980; Wong and Prince, 1978). Moreover, because DA effects are, in part, contingent on cell activity, the dopaminergic system in the hippocampus would be most effective in modulating the activities of cells exhibiting high levels of excitability. In some hippocampal pyramidal neurons, burst generation is the usual mode of cell discharge (Kandel and Spencer, 1961; Wong and Prince, 1978). Synchronous burst generation occurs in populations of hippocampal pyramidal neurons spontaneously following acetylcholine application (Benardo and Prince, 1981) or after exposure to convulsant agents (Yamamoto, 1972; Schwartzkroin and Prince, 1977, 1980). AHPs mediated by the $\mathrm{Ca}^{2+}$-activated $\mathrm{K}^{+}$conductance probably play an important role in terminating each burst and also in setting the interburst interval (Wong and Prince, 1978; Alger and Nicoll, 1980a; Hotson and Prince, 1980, 1981). Long duration DA-induced increases in the amplitude and duration of the AHP and its associated conductance therefore would tend to shorten hursts and lengthen interburst intervals and would have an important modulatory influence on the cyclical excitability of hippocampal pyramidal neurons.

\section{References}

Alger, B. E., and R. A. Nicoll (1979) GABA-mediated biphasic inhibitory responses in hippocampus. Nature 281: 315-317.

Alger, B. E., and R. A. Nicoll (1980a) Epileptiform burst afterhyperpolarization: Calcium-dependent potassium potential in hippocampal CA1 pyramidal cells. Science 210: 1122-1124.

Alger, B. E., and R. A. Nicoll (1980b) Spontaneous inhibitory postsynaptic potentials in hippocampus: Mechanisms for tonic inhibition. Brain Res. 200: 195-200. 
Andersen, P., R. Dingledine, L. Gjerstad, I. A. Langmoen, and A. Mosfeldt-Laursen (1980) Two different responses of hippocampal pyramidal cells to application of gamma-aminobutyric acid. J. Physiol. (Lond.) 305: 279-296.

Benardo, L. S., and D. A. Prince (1981) Acetylcholine induced modulation of hippocampal pyramidal neurons. Brain Res. 211: 227-234.

Benardo, L. S., and D. A. Prince (1982) Long term modulation of intrinsic membrane properties of hippocampal neurons. In Conditioning: Representation of Involved Neural Functions, C. D. Woody, ed., Plenum Press, New York, in press.

Bernardi, G., M. G. Marciani, C. Morcutti, F. Pavone, and P. Stanzione (1978) The action of dopamine on rat caudate neurones intracellularly recorded. Neurosci. Lett. 8: 235-240.

Biscoe, T. J., and D. W. Straughan (1966) Micro-electrophoretic studies of neurones in the cat hippocampus. J. Physiol. (Lond.) 183: 341-359.

Blaustein, M. P. (1976) The ins and outs of calcium transport in squid axons: Internal and external ion activation of calcium efflux. Fed. Proc. 35: 2574-2578.

Caroni, P., and E. Carafoli (1980) An ATP dependent $\mathrm{Ca}^{2+}$ pumping system in dog heart sarcolemma. Nature 283: 765767.

DiPolo, R. (1978) Ca pump driven by ATP in squid axons. Nature 274: 390-392.

Dolphin, A., and J. Bockaert (1981) $\beta$-Adrenergic receptors coupled to adenylate cyclase in cat hrain: Regional distribution, pharmacological characteristics and adaptive responsiveness. In Recent Advances in the Pharmacology of Adrenoceptors, E. Szabadi, C. M. Bradshaw, and P. Bevan, eds., p. 1978, Elsevier/North-Holland, Amsterdam.

Gallagher, J. P., H. Inokuchi, and P. Shinnick-Gallagher (1980) Dopamine depolarization of mammalian primary afferent neurones. Nature 283: 770-772.

Ginsborg, B. L., C. R. House, and M. R. Milchell (1980) On the role of calcium in the electrical responses of the cockroach salivary gland cells to dopamine. J. Physiol. (Lond.) 303: 325335.

Gorman, A. L. F., and M. V. Thomas (1980) Potassium conductance and internal calcium accumulation in a molluscan neurone. J. Physiol. (Lond.) 308: 287-313.

Gutnick, M. J., and D. A. Prince (1981) Dye-coupling and possible electrotonic coupling in the guinea pig neocortex. Science 211: 67-70.

Hablitz, J. J. (1981) Effects of intracellular injections of chloride and EGTA on postepileptiform-burst hyperpolarizations in hippocampal neurons. Neurosci. Lett. 22: 159-163.

Herrling, P. L. (1981) The membrane potential of cat hippocampal neurons recorded in vivo displays four different reactionmechanisms to iontophoretically applied transmitter agonists. Brain Res. 212: 331-343.

Herrling, P. L., and C. D. Hull (1980) Iontophoretically applied dopamine depolarizes and hyperpolarizes the membrane of cat caudate neurons. Brain Res. 192: 441-462.

Herrling, P. L., C. D. Hull, and N. A. Buchwald (1978) Some effects of putative neurotransmitters on the membrane of cat caudate neurons. Neurosci. Lett. Suppl. 1: 5258.

Hotson, J. R., and D. A. Prince (1980) A calcium-activated hyperpolarization follows repetitive firing in hippocampal neurons. J. Neurophysiol. 43: 409-419.

Hotson, J. R., and D. A. Prince (1981) Penicillin- and bariuminduced epileptiform bursting in hippocampal neurons: Actions on $\mathrm{Ca}^{2+}$ and $\mathrm{K}^{+}$potentials. Ann. Neurol. 10: 11-17.

Hotson, J. R., D. A. Prince, and P. A. Schwartzkroin (1979) Anomalous inward rectification in hippocampal neurons. J. Neurophysiol. 42: 889-895.

Hyttel, J. (1980) Further evidence that ${ }^{3} \mathrm{H}$-cis $(\alpha)$ flupenthixol binds to the adenylate cyclase-associated receptor (D-1) in rat corpus striatum. Psychopharmacology (Berlin) 67: 107109.

Iversen, L. I. (1975) Dopamine receptors in the brain. Science 188: 1084-1089.

Johnston, D., J. J. Hablitz, and W. A. Wilson (1980) Voltage clamp discloses slow inward current in hippocampal burstfiring neurones. Nature 286: 391-393.

Kandel, E. R., and W. A. Spencer (1961) Electrophysiology of hippocampal neurons. I. Afterpotentials and repetitive firing. J. Neurophysiol. 24: 243-259.

Kitai, S. T., M. Sugimori, and J. D. Kocsis (1976) Excitatory nature of dopamine in the nigro-caudate pathway. Exp. Brain Res. 24: 351-363.

Krnjevic, K., E. Puil, and R. Werman (1978) EGTA and motoneuronal after-potentials. J. Physiol. (Lond.) 275: 199-223.

Meech, R. W. (1978) Calcium-dependent potassium activation in nervous tissue. Annu. Rev. Biophys. Bioeng. 7: 1-18.

Nathanson, J. A. (1977) Cyclic nucleotides and nervous system function. Physiol. Rev. 57: 157-256.

Nicoll, R. A., and B. E. Alger (1981) Synaptic excitation may activate a calcium-dependent potassium conductance in hippocampal pyramidal cells. Science 212: 957-959.

Phillis, J. W. (1977) The role of cyclic nucleotides in the CNS Can. J. Neurol. Sci. 4: 151-195.

Rasmussen, H. (1970) Cell communication, calcium ion, and cyclic adenosine monophosphate. Science 170: 404-412.

Rasmussen, H., and D. B. P. Goodman (1977) Relationships between calcium and cyclic nucleotides in cell activation. Physiol. Rev. 57: 421-509.

Scatton, B., H. Simon, M. LeMoal, and S. Bischoff (1980) Origin of dopaminergic innervation of the rat hippocampal formation. Neurosci. Lett. 18: 125-131.

Schwab, M. E., F. Javay-Agid, and Y. Agid (1978) Labeled wheat germ agglutinin as a new, highly sensitive retrograde tracer in the rat brain hippocampal system. Brain Res. 152: 145-150.

Schwartzkroin, P. A. (1975) Characteristics of CA1 neurons recorded intracellularly in the hippocampal in vitro slice preparation. Brain Res. 128: 53-68.

Schwartzkroin, P. A., and D. A. Prince (1977) Penicillin-induced epileptiform activity in the hippocampal in vitro preparation. Ann. Neurol. 1: 463-469.

Schwartzkroin, P. A., and D. A. Prince (1980) Changes in excitatory and inhibitory synaptic potentials leading to epileptogenic activity. Brain Res. 183: 61-76.

Schwartzkroin, P. A., and C. E. Stafstrom (1980) Effects of EGTA on the calcium activated afterhyperpolarization in hippocampal CA3 pyramidal cells. Science 210: 1125-1126.

Seeman, P. (1980) Brain dopamine receptors. Pharmacol. Rev. 32: $229-313$.

Segal, M. (1981) The action of norepinephrine in the rat hippocampus: Intracellular studies in the slice preparation. Brain Res. 206: 107-128.

Segal, M., and F. E. Bloom (1974) Norepinephrine in the rat hippocampus. I. Iontophoretic studies. Rrain Res. 72: 79-97.

Segal, M., V. Greenberger, and R. Hofstein (1981) Cyclic AMP. generating systems in rat hippocampal slices. Brain Res. 213: $351-364$.

Simon, H., M. Le Moal, and A. Calas (1979) Efferents and afferents of the ventral tegmental-A10 region studied after local injection of $\left[{ }^{3} \mathrm{H}\right]$ leucine and horseradish peroxidase. Brain Res. 178: 17-40.

Swanson, L. W., and B. K. Hartman (1975) The central adrenergic system. An immunofluorescence study of the location of cell bodies and their efferent connections in the rat utilizing dopamine- $\beta$-hydroxylase as a marker. J. Comp. Neurol. 163: 467-505.

Thomas, R. C. (1972) Electrogenic sodium pump in nerve and 
muscle cells. Physiol. Rev. 52: 563-594.

Wong, R. K. S., and D. A. Prince (1978) Participation of calcium spikes during intrinsic burst firing in hippocampal neurons. Brain Res. 159: 385-390.

Wong, R. K. S., and D. A. Prince (1979) Dendritic mechanisms underlying penicillin-induced epileptiform activity. Science 204: 1228-1231.

Wong, R. K. S., and D. A. Prince (1981) Afterpotential gener- ation in hippocampal pyramidal cells. J. Neurophysiol. 45: 86-97.

Wyss, J. M., L. W. Swanson, and W. M. Cowan (1979) A study of subcortical afferents to the hippocampal formation in the rat. Neuroscience 4: 463-476.

Yamamoto, C. (1972) Intracellular study of seizure-like afterdischarges elicited in thin hippocampal sections in vitro. Exp. Neurol. 35: 154-164. 